\title{
Long term outcomes of radial artery grafting in patients undergoing coronary artery bypass surgery
}

\author{
James Tatoulis ${ }^{1}$, Thomas A. Schwann ${ }^{2}$ \\ ${ }^{1}$ Department of Surgery, University of Melbourne, Melbourne, Australia; ${ }^{2}$ Department of Surgery, University of Toledo College of Medicine and \\ Life Sciences, Toledo, OH, USA \\ Correspondence to: James Tatoulis, MD. Department of Surgery, Suite 28, Medical Centre, Royal Melbourne Hospital, 300 Grattan Street, Parkville, \\ Melbourne VIC 3050, Australia. Email: james.tatoulis@mh.org.au.
}

\begin{abstract}
Single arterial left internal thoracic artery (LITA) based coronary artery bypass surgery (LITA-SABG) has been the principal revascularization strategy for over 25 years across all patient demographics. In line with the current emphasis being placed on personalized medicine, which tailors individual, patient-specific therapy to optimize outcomes, coronary artery bypass grafting (CABG) techniques have also evolved to achieve enhanced results among specific groups of patients with coronary artery disease. Most notable has been the development of multi-arterial bypass grafting (MABG) techniques, using either the radial artery (RA) or the right internal thoracic artery (RITA) in conjunction with the LITA, as both techniques have been shown to enhance long term survival of CABG patients. This article reviews the latest data on the long-term outcomes of RA-MABG and considers its impact in various sub-cohorts of CABG that are increasingly being treated by cardiac surgeons. The primary aim of this review is to highlight the advantages of RA-MABG over LITA-SABG and thereby potentiate its adoption into clinical practice. Our secondary aim is to summarize the results of RA-MABG in specific CABG sub-cohorts, to more closely align CABG surgery with the emerging consensus that personalized medicine enhances healthcare value.
\end{abstract}

Keywords: Coronary bypass; radial arteries; multiple arterial grafting

Submitted Feb 22, 2018. Accepted for publication May 23, 2018.

doi: 10.21037 /acs.2018.05.11

View this article at: http://dx.doi.org/10.21037/acs.2018.05.11

\section{Radial artery as a coronary conduit-background}

Carpentier first reported the use of the radial artery (RA) in coronary artery bypass graft (CABG) in 1971 (1). Shortly thereafter, however, the same group abandoned its use due to poor durability. Acar et al., two decades later, resurrected the use of the RA as a coronary graft based on unexpectedly excellent patency data from the original series from the 1970s (2). Since then, given its excellent patency, ease of harvest-by open or endoscopic techniques-ease of handling, ability to reach all and any coronary targets and no increased risk of sternal wound complications, RAmultiple arterial bypass grafting (RA-MABG) has grown in popularity such that it is the second most frequently used grafting strategy in the STS database over the last decade (3), following the traditional left internal thoracic artery-single arterial bypass grafting (LITA-SABG) approach.

The RA is typically $22 \mathrm{~cm}$ long, slightly larger $(2.2$ versus $2.0 \mathrm{~mm}$ distal internal lumen diameter) and has a thicker wall and media (200 versus $80 \mu)$ than the right internal thoracic artery (RITA). It also tends to respond to vasoconstrictors and vasodilators with greater magnitude. RA-specific anatomic and physiologic factors have been hypothesized to increase its value as a coronary graft compared to saphenous vein grafts (SVG). These include: production of nitric oxide, with potential protective effects on downstream native coronary artery disease (4), enhanced resistance to atherosclerosis $(5,6)$, minimized size mismatch between the RA and the coronary target and the transformation of the RA from a muscular artery to an elasto-muscular artery with a decrease in the smooth muscle components in its media following implantation 
into the coronary circulation (7). To optimize its benefits, the RA must be deployed judiciously, given concerns about its potential to vasospasm and prematurely fail due to competitive flow through the target vessel. With the increasing use of the RA as an access point for diagnostic coronary angiography and therapeutic intervention, concern for decreased graft durability following trans-radial catheterization will also need to be carefully studied $(8,9)$.

Based on the latest data, the use of RA as a conduit in CABG surgery has been incorporated into multiple practice guidelines, with a Class of Recommendation IIa-IIb and Level of Evidence B (10-12).

\section{RA-MABG; graft patency}

Graft patency has traditionally been thought to determine clinical outcomes and is influenced not only by the specific conduit used, but also by the territory grafted, the degree of coronary stenosis, the amount of competitive flow in the target vessel, and surgical-specific technical factors.

\section{Randomised control trials (RCTs) of RA patency}

Three large RCTs of RA patency reported results beyond 5 years post-operatively and all showed superior patency for the RA over the SVG.

In the radial artery versus saphenous vein patency (RSVP) study, perfect RA patency at 5 years was $92 \%$ compared to $78 \%$ for SVG $(\mathrm{P}=0.04)$ (13).

The Canadian Radial Artery Patency Study (RAPS) similarly showed better RA patency over SVG at 7 years-91.1\% versus $81.4 \%$, $(\mathrm{P}=0.002)$, respectively (14).

The Australian radial artery patency and clinical outcomes (RAPCO) trial also showed the RA to have superior patency over SVG at 7 years (92\% versus $84 \%$ ) $(\mathrm{P}=0.039)$, and similar patency to RITA-90\% versus $88 \%$ at 8 years $(\mathrm{P}=0.19)$. Importantly, the $\mathrm{SVG}$ patency in this trial was higher than reported in other studies and may reflect that only the best available SVG conduits were utilized and were harvested by a consultant surgeon and were placed to the second most important target vessels (15).

Well conducted meta-analyses of RCTs have also shown that the RA was more likely to be patent than SVG beyond 4 years $-89 \%$ versus $63 \%$ (16). In a meta-analysis of 35 studies (including $11 \mathrm{RCTs}$ ), Athanasiou et al. reported a marked and important patency advantage for RA over SVG (17), as did Benedetto et al. (9 RCTs), who also found similar patencies for RA and RITA (18).
RA patency is best when grafted to a coronary artery with a high-grade stenosis, preferably $>80 \%$, or where the minimal luminal diameter of the target vessel at the most severe point of stenosis is $<0.7 \mathrm{~mm}(6,7)$.

\section{Observational studies of RA patency}

Numerous observational studies have documented excellent RA patency of $89 \%$ at 10 years, and $86 \%$ at 20 years $(5,6,19)$. Almost invariably, the long-term patent RAs are uniform, smooth, and free of atheroma (unlike SVG) (5-7). Thus, the durability of RA grafts is vastly superior compared to SVG within the same cohorts of patients, with reported patency rates ranging from $47 \%$, to $60 \%$ at 10 years and $35 \%$ or below at 15 years. Those SVG still patent almost always are atheromatous, with extensive luminal irregularities (20).

In general, RA, LITA, and RITA patencies are identical when used in the same manner, at the same location and under similar circumstances. At 10 years, patency of the 3 arterial grafts to the LAD is $95 \%$, to the circumflex marginal system $90-92 \%$, and to the distal RCA/PDA (RITA or RA) $80-90 \%(6,19,20)$. More broadly, RA patency rates are consistently $>90 \%$ in the long term when the native coronary artery stenosis was $>90 \%(5,6,14,19)$.

Once RAs have been deployed and are patent in the early post-operative period (i.e., there are no technical nor competitive flow issues), they tend to remain free of atheroma and are patent into the long-term (5-8,13-15,19,20). In contrast, SVGs develop progressive occlusive changes, with initial sub-intimal proliferation and then progressive atheroma and thrombosis with eventual occlusion over $5-15$ years $(14,20)$.

Contemporary randomised and observational studies show SVG failure rates of $10 \%$ at 1 week, $26 \%$ at 12 months and $50-60 \%$ by 10 years. SVG failure rates are even higher when harvested by endoscopic techniques, and in off-pump CABG (21).

\section{RA-MABG: long-term clinical results}

In addition to graft patency, clinical outcomes following CABG are influenced by age, comorbidities (e.g., diabetes, hypertension, renal disease, etc.) and the degree of left ventricular dysfunction. RA grafting in CABG is typically accomplished in combination with other grafts. Graft combinations in order of decreasing frequency are: $\mathrm{LITA} / \mathrm{RA} \pm \mathrm{SVG}$, bilateral ITA/RA $\pm \mathrm{SVG}, \mathrm{LITA} /$ bilateral $\mathrm{RA} \pm \mathrm{SVG}$, and rarely in combination with a gastro-epiploic 
artery. LITA/RA Y grafts and sequential grafting are also frequently used.

Patient survival with RA-MABG has been reported in the range of $90 \%$ to $94 \%$ at 5 years, $85 \%$ to $90 \%$ at 10 years and $67 \%$ to $76 \%$ at 15 years. In each instance, the survival is significantly better with RA use as a second arterial graft, compared to the traditional single arterial LITA-SABG $(70-75 \%$ at 10 years, $60-70 \%$ at 15 years) $(5,6,22,23)$. Tranbaugh and co-workers documented survival rates of $89 \%$ and $75 \%$ at 10 and 15 years for RA-MABG (24). Grau et al. found similar survival of $92 \%$ at 10 years (25).

In recent, large population studies conducted in California with 5,813 CABG patients with RA-MABG, survival was $89.5 \%$ at 7 years (26). From Australia, the Melbourne group, (Tatoulis et al.) reported survival of $93 \%$ at 5 years, and $87 \%$ at 10 years in 9,935 RA-MABG patients (27). In Canada, ( $\mathrm{n}=20,076-5,580$ with RA-MABG), Pu et al. found RA-MABG 15 -year survival to be $74 \%$ (28).

\section{Clinical outcomes with RA versus saphenous vein as the second graft}

Early patency and survival are similar. Survival curves diverge beyond the 7th post-operative year. Ten-year survival reports of RA-MABG show marked benefit over LITA-SABG, with typical survival being $85 \%$ to $90 \%$, as opposed to $70 \%$ to $75 \%$ at 10 years, respectively. Habib, Schwann and colleagues reported 9-year survival rates of $89 \%$ for RA-MABG, versus $69 \%$ for LITA-SABG. This is representative of many other experiences (29).

Furthermore, RA-MABG is associated with fewer major adverse cardiac events (MACE), less recurrent angina, fewer re-operations, fewer myocardial infarcts (MI) and less need for repeat re-vascularisation $(5,6,23,27)$. Additionally, there are no leg wound infections with RA-MABG and RA harvest site infections are extremely rare $(6,13)$. Conversely, SVGs procured endoscopically are associated with even poorer patency and inferior clinical results (21). For every 100 patients operated on, there will be 5 to 10 more patients alive at 10 years (depending on age and co-morbidities) if RA-MABG as opposed to LITA-SABG is used $(22,23,27)$.

\section{RA-MABG versus BITA-MABG; choosing the optimal grafting strategy for each patient- personalized medicine in CABG?}

There appears to be an equipoise between the RA and RITA (30). The RAPCO randomized trial showed similar patency and long-term clinical results when either RA or RITA was used as the second arterial graft to the second most important coronary in patients $<70$ years of age (15).

Multiple observational studies either show similar patencies and outcomes, or minor advantages of one over the other. The New York group (Tranbaugh et al.) found slight survival benefit for RA-MABG over BITA-MABG with $85 \%$ versus $80 \%$ at 10 years, and $76 \%$ versus $71 \%$ at 15 years $(\mathrm{P}=0.60)$ (24). Conversely, others have reported the opposite. Navia and co-workers found a slight survival advantage for BITA-MABG over RA-MABG, $88 \%$ versus $83 \%$ at 7 years $(\mathrm{P}=0.65)$, but more so for combined end points that also included re-intervention and re-admission (31).

These slight variations in results may reflect early learning experiences and different methods of deployment. The factors that may influence RITA patency and outcomes include its length, delicacy, higher rates of sternal infection, territory grafted, and whether it is used as an in situ, free, or a Y-graft. Factors influencing RA performance include a greater propensity to spasm, a greater likelihood to be deployed to the posterior descending or circumflex coronary arteries (length affecting flow dynamics), the effect of native coronary stenosis, or minimal diameter at the point of stenosis, and competitive flow. RITA patency appears to be less affected by coronary stenosis and competitive flow $(15,19,20)$. An area of prior inferior infarction is more likely to be re-vascularised with a RA rather than a RITA, and this may modify or negate expected benefits (6).

RA-MABG may be more appealing than BITA-MABG for both patients and surgeons, as the left RA can be harvested simultaneously with the LITA, is longer and more versatile than the RITA $(5,6,22,24)$, and is associated with fewer deep sternal wound infections, although these can be substantially overcome by skeletonized ITA harvesting (32). Thus, RA-MABG maybe preferable in diabetic patients and those who are at higher risk of deep sternal wound infections, while BITA-MABG may be the more appropriate grafting strategy to target vessels with moderate stenosis, especially if it can be used in an in situ configuration.

\section{Is there a need for a third arterial graft or total arterial revascularisation (TAR)?}

As the benefits of multiple arterial bypass grafting crystalize, a number of groups aim for TAR, if possible. This can be achieved with bilateral ITAs (usually in a Y configuration), BITA supplemented with an RA graft or LITA with 
bilateral RAs and/or the gastro-epiploic artery.

Recent reports make the case that three arterial grafts are better than two. Grau and colleagues noted improved survival for BITA/RA over BITA + SVG beyond 10 years-92\% versus $87 \%$ at 12 years (25). It took 10 years to find a survival advantage of two ITAs over one. Similarly, the survival advantage of three arterial grafts or TAR to be noted over BITA-MABG or RA-MABG may take at least a decade post-operatively. Shi et al. also reported better survival for BITA/RA over BITA + SVG, in matched groups, with $90 \%$ compared to $81 \%$ at 10 years, and $82 \%$ versus $72 \%$ at 15 years $(\mathrm{P}=0.021)$ (33).

In a comprehensive meta-analysis ( 8 propensity score matched studies) comparing 2 against 3 arterial grafts, followed for up to 16 years, Gaudino found identical, excellent peri-operative results, but a significant, $20 \%$ $(\mathrm{HR}=0.80, \mathrm{P}<0.001)$ late survival advantage for the 3 arterial graft cohorts (34). The CAGB "holy grail" should be total arterial grafting if possible, and if appropriate.

\section{RA-MABG: long-term outcomes in specific CABG sub-cohorts}

\section{Is a radial artery usable in CABG following previous trans-radial catbeterization?}

Radial arteries are increasingly being used for diagnostic coronary studies and percutaneous interventions in preference to the traditional trans-femoral approach. Trans-radial access (TRA) has been associated with a substantial decrease in periprocedural vascular access site complications and transfusion requirements compared to the trans-femoral approach (35). Most importantly, decreased mortality risk has been reported with TRA in patients presenting with an acute coronary syndrome (36). Despite these advantages, TRA has been associated with a small risk (5-8\%) of RA occlusion (37) and concerns have been raised in small studies that the instrumentation associated RA intimal trauma may lead to poor graft patency when it is subsequently used as a coronary graft (38-40). In addition, there is emerging data that TRA may result in persistent adverse impacts on the vasodilatory capacity of the RA for a prolonged time following TRA (8). Until further data becomes available, surgeons should use a previously instrumented RA with caution. An integrated Heart Team approach to increasingly complex patients with coronary artery disease should ensure that the mutually exclusive priorities of trans-radial catheterization and RA use as coronary grafts be reconciled.

\section{RA-MABG in diabetics}

Given the explosion in the incidence of diabetes mellitus worldwide, diabetes is increasingly prevalent among patients undergoing CABG, reaching $47 \%$ of all patients in the STS database undergoing isolated CABG (3). Diabetics have a worse survival following CABG than non-diabetics and those who are insulin dependent have the worst survival (41). Given the association of increased deep sternal wound infections in diabetic patients undergoing BITA grafting (42), RA is frequently used in diabetics undergoing CABG. In 2014, $45 \%$ of CABG patients undergoing RA-MABG were diabetics versus $33 \%$ of BITA-MABG patients. Thus, the impact of RA use in this patient cohort is of considerable interest, yet the data on the impact of RA in diabetics is limited. In a highly restricted (with perfect matching among 5 chosen factors: gender, insulin use, three-vessel coronary disease, pre-op renal failure and left ventricular dysfunction) propensity matched diabetic population undergoing either the traditional LITA-SABG or RA-MABG, long term survival (up to 16 years) was significantly $(\mathrm{P}=0.012)$ improved with RA use preferentially over the SVG. This survival advantage was driven by an improvement in the outcomes of non-insulin dependent patients $(\mathrm{P}=0.007)$, with no impact on survival in patients who required insulin $(\mathrm{P}=0.61)$. A sensitivity analysis documented an RA associated survival advantage in diabetics who were male, those with three vessel diseases and those with preserved ejection fraction. It has been suggested that the noted survival benefit is the result of a superior RA versus SVG patency noted in the general CABG population, which is even further exaggerated in diabetics (43). Diabetes did not impact RA patency, while SVG patency was much worse among diabetics compared to non-diabetics. These superior RA patency data and longterm survival advantages have been reported despite the observations of RA endothelial dysfunction in patients with diabetes (44). Raza reported equivalent long-term survival in diabetics undergoing BITA-MABG as with RA-MABG (45).

\section{RA-MABG in males versus females}

RA-MABG is beneficial in both male and female CABG patients and compared to LITA-SABG, improves longterm survival in both men and women in most, but not all, studies. Lawton et al. observed a 5-year survival advantage with RA-MABG despite increased technical complexity of this strategy, due the typically smaller female radial arteries and lower intra-operative graft flow measurements 
compared to males (46). Dimitrova et al. also found improved long-term survival in 566 propensity matched female patients undergoing RA-MABG compared to LITA-SABG (47). Schwann et al. reported improved longterm survival in both males and females undergoing RAMABG compared to LITA-SABG, but with a distinctly different magnitude and chronology. Women and men had a $25 \%$ and $35 \%$ relative long-term (12-year) survival advantage with RA-MABG, respectively. In men, this survival advantage first appeared 3 years post-operatively and persisted throughout the rest of the study period. In contrast in women, the RA-MABG survival advantage appeared in three phases: an early survival advantage within the first post-operative year, followed by a $12-36$-month survival disadvantage and a final long-term decrement in mortality risk (48). Pullan, in a large study of 13,369 patients, found RA-MABG improved survival only in men. In that analysis, the survival of women undergoing LITASABG and RA-MABG was equivalent. Several important determinants of long-term survival, such as the number of arterial grafts, were not included in their risk adjustment methodologies and the propensity matching was rather loose with a caliper of only 0.2 (49). Importantly, all studies (46-49) confirmed the peri-operative safety of RA-MABG among women, noting that peri-operative mortality was similar to LITA-SABG.

\section{RA-MABG in the elderly}

In light of the current aging population, the elderly are likely to more frequently undergo CABG moving into the future. CABG remains a reasonable and durable revascularization strategy among the elderly (50) and the very elderly (51). Although octogenarian CABG patients have a life expectancy equivalent to that of the general aged matched population, given the shorter time horizon for ascertaining success in elderly patients, there has been skepticism about the role of any form of MABG in this patient demographic, as its survival advantage may not be apparent for up to a decade post-operatively, as has been shown in the case of BITA-MABG versus LITA-SABG (52). Importantly, RA-MABG time segmented survival advantage analysis has shown that the time horizon for RA-MABG survival advantage is much shorter and in fact, the overall long-term survival advantage is principally driven in the intermediate post-operative time period $(0.5-5$ years postoperatively) with equivalent survival in the early and longterm post-operative time periods (53). In spite of these concerns, Kurlansky et al. noted a survival advantage in patients older than 75 with BITA-MABG compared to the traditional LITA-SABG (54) and Habib et al. (29) noted that, compared to LITA-SABG, RA-MABG was associated with an appreciable $53 \%$ relative reduction in 12-year mortality in patients over the age of 70 , with a smaller, but still significant, RA-MABG survival advantage among octogenarians. Importantly, there was no increased risk of perioperative mortality with RA-MABG. The Melbourne group also reported better 10 -year survivals, $68 \%$ versus $52 \%(\mathrm{P}=0.008)$ for RA-MABG in 507 matched elderly pairs (mean age, 71 years) (55).

\section{Preventing vasospasm in radial artery grafting}

In light of the substantial smooth muscle content of the RA media, an ongoing concern about the long-term durability has been the possible role of vasospasm in genesis of a "string sign" which may be further exacerbated by competitive flow in the native target artery downstream from a moderate stenotic lesion. To overcome RA spasm, traditionally, intravenous vasodilators were initiated in the operating room and continued as oral agents for a variable period post-operatively. The emergence of calcium channel antagonists has been credited with minimizing RA vasospasm and in part, the superior RA patency noted in the 1990s compared with what had been described previously. This experience has resulted in the incorporation of antispasm agent use into the STS clinical practice guidelines on arterial conduits (12). In addition to calcium channel antagonists and nitrates, phenoxybenzamine, milrinone and papaverine have also been used for this purpose (6).

Despite the physiologically sound basis for their wide spread use, the efficacy of anti-spasm agents on clinically meaningful endpoints is poorly defined. This is particularly so, given the morphologic transformation of the RA once placed into the coronary circulation from a muscular artery into an elasto-muscular artery, with a decrease in the muscular elements within its media (7). Associated with this, RAs transposed into the coronary circulation also are less sensitive to vasoconstrictor agents compared to RA in situ. Moreover, calcium channel antagonists started in the immediate post-operative period had no impact on myocardial perfusion or early RA graft patency. Calcium channel antagonists were also not effective in preventing RA vasospasm following endovascular serotonin infusion, a potent vasoconstrictor, and had no impact on 5-year clinical or angiographic outcomes (56). The potential beneficial 
effects of vasodilators must be balanced by their tendency to cause hypotension, especially when combined with the protocol driven post-operative management of CABG patients, which includes beta blockers and angiotensin converting enzyme inhibitors. Concurrent with the lack of effectiveness of antispasmodic agents in preventing clinically significant vasospasms, our group gradually abandoned the use of systemic calcium channel antagonists and for the last decade, we have exclusively used verapamil in the bath used for RA storage following harvesting as the only antispasmodic agent. We have not encountered any clinically significant problems with RA vasospasm with this approach, even in those patients that require vasoconstrictor agents in the peri-operative period. This stands in contrast with the practice pattern of the one of the authors (JT), which includes the routine use of anti-spasm agents with RA-MABG for 6 months post-operatively $(6,20)$.

\section{Conclusions}

The radial artery is an important, though under-used, conduit in coronary bypass surgery. It should be part of every coronary surgeons skill set. It can be harvested and used exactly as a SVG would be, is not associated with any increased peri-operative morbidity nor mortality, has far better long-term patency, and it is associated with superior long-term survival as opposed to SVG. RA use extends possibilities of multi-arterial and total arterial revascularization in those patients in whom bilateral ITAs are contraindicated, such as morbidly obese diabetic patients and those with chronic obstructive pulmonary artery disease. In addition, the RA is extremely useful in re-operative coronary surgery, where traditional conduits may not be available. Its efficacy has been documented in multiple CABG patient subcohorts. To optimize results with RA grafting, anti-spasm prophylaxis may be considered, but its efficacy, at present, remains poorly defined and competitive flow must be avoided. RA should be used as a coronary graft with extreme caution following trans-radial catheterization.

\section{Acknowledgements}

None.

\section{Footnote}

Conflicts of Interest: The authors have no conflicts of interest to declare.

\section{References}

1. Carpentier A, Guermonprez JL, Deloche A, et al. The aorta-to-coronary radial artery bypass graft: a technique avoiding pathological changes in grafts. Ann Thorac Surg 1973;16:111-21.

2. Acar C, Jebara VA, Portoghese M, et al. Revival of the radial artery for coronary artery bypass grafting. Ann Thorac Surg 1992;54:652-9.

3. Schwann TA, Tatoulis J, Puskas J, et al. Worldwide trends in multi arterial CABG surgery 2004-2016: A tale of two continents. Semin Thorac Cardiovasc Surg 2017;29:273-80.

4. Dimitrova KR, Hoffman DM, Geller CN, et al. Arterial Grafts Protect the Native Coronary Vessels from Atherosclerotic Disease Progression. Ann Thorac Surg 2012;94:475-81.

5. Achouh P, Isselmou KO, Boutekadjirt R, et al. Reappraisal of a 20-year experience with radial artery as a conduit for coronary bypass grafting. Eur J Cardiothorac Surg 2012;41:87-92.

6. Tatoulis J, Buxton BF, Fuller JA, et al. Long-term patency of 1108 radial arterial-coronary angiograms over 10 years. Ann Thorac Surg 2009;88:23-9.

7. Gaudino M, Prati F, Caradonna E, et al. Implantation in coronary circulation induces morphofunctional transformation of radial grafts from muscular to elastomuscular. Circulation 2005;112:I-208-211.

8. Antonopoulos AS, Latsios G, Oikonomou E, et al. Long-term endothelial dysfunction after trans-radial catheterization: A meta-analytic approach. J Card Surg 2017;32:464-73.

9. Lazar HL. The use of the radial artery following transradial catheterization--A word of caution. J Card Surg 2017;32:474-5.

10. Hillis LD, Smith PK, Anderson JL, et al. 2011 ACCF/ AHA guideline for coronary artery bypass surgery: Executive Summary: A report of the American College of Cardiology Foundation/American Heart Association Task Force on Practice Guidelines. Circulation 2011;124:2610-42.

11. Windecker S, Kolh P, Alfonso F, et al. 2014 ESC/EACTS guidelines on myocardial revascularization. Eur Heart J 2014;35:2541-619.

12. Aldea GS, Bakaeen FG, Pal J, et al. The Society of Thoracic Surgeons clinical practice guidelines on arterial conduits for coronary artery bypass grafting. Ann Thorac Surg 2016;101:801-9. 
13. Collins P, Webb CM, Chong CF, et al. Radial Artery Versus Saphenous Vein Patency Randomised Trial. 5 Year Angiographic Follow Up. Circulation 2008;117:2859-64.

14. Deb S, Cohen EA, Singh SK, et al. Radial artery and Saphenous Vein Patency More Than 5 Years after Coronary Artery Bypass Surgery: Results from the RAPS (Radial Artery Patency Study). J Am Coll Cardiol 2012;60:28-35.

15. Hayward PA, Gordon IR, Hare DL, et al. Comparable Patencies of the Radial Artery and Right Internal Thoracic Artery or Saphenous Vein Beyond 5 Years. Results from the Radial Artery Patency and Clinical Outcomes Trial. J Thorac Cardiovasc Surg 2010;139:60-5.

16. Cao C, Manganas C, Horton M, et al. Angiographic Outcomes of Radial Artery versus Saphenous Vein in Coronary Artery Bypass Graft Surgery: A Meta-Analysis of Randomised Controlled Trials. J Thorac Cardiovasc Surg 2013;146:255-61.

17. Athanasiou T, Sasso S, Rao C, et al. Radial artery versus saphenous vein conduits for coronary bypass surgery 40 years of competition, which conduit offers better patency? A systematic review and meta-analysis. Eur J Cardiothorac Surg 2011;40:208-20.

18. Benedetto U, Raja SG, Albanese A, et al. Searching for the second-best graft in coronary artery bypass surgery: A network meta-analysis of randomized controlled trials. Eur J Cardiothorac Surg 2015;47:59-65.

19. Gaudino M, Tondi P, Benedetto U, et al. The Radial Artery as a Coronary Artery Bypass Conduit. 20 Year Results. J Am Coll Cardiol 2016;68:603-10.

20. Tatoulis J, Buxton BF, Fuller JA. Patencies of 2,127 Arterial to Coronary Conduits Over 15 years. Ann Thorac Surg 2004;77:93-101.

21. Mehta RH, Ferguson TB, Lopes RD, et al. Saphenous vein grafts with multiple versus single distal targets in patients undergoing coronary artery bypass graft surgery: 1 year graft failure and 5 year outcomes from the project of Ex - VIVO vein graft engineering via transfection. (PREVENT) trial. Circulation 2011;124:280-8.

22. Schwann TA, Trambaugh RF, Dimitrova KR, et al. Time varying survival benefit of radial artery versus venous grafting: A multi institutional analysis. Ann Thorac Surg 2014;97:1328-34.

23. Buxton BF, Shi WY, Tatoulis J, et al. Total Arterial Revascularisation with Internal Thoracic and Radial Artery Grafts in Triple Vessel Coronary Artery Disease is Associated with Improved Survival. J Thorac Cardiovasc Surg 2014;148:1238-43.
24. Tranbaugh RF, Dimitrova KR, Lucido DJ, et al. The Second Best Arterial Graft: A Propensity Analysis of The Radial Artery Versus the Free Right Internal Thoracic Artery to Bypass the Circumflex Coronary Artery. J Thorac Cardiovasc Surg 2014;147:133-40.

25. Grau JB, Kuschner CE, Johnson CK, et al. The effects of using a radial artery in patients already receiving bilateral internal mammary arteries during coronary bypass grafting: 30 day outcomes and 14 year survival in a propensity matched cohort. Eur J Cardiothorac Surg 2016;49:203-10.

26. Goldstone AB, Chiu P, Baiocchi M, et al. Second Arterial versus Venous Conduits for Multi-Vessel Coronary Artery Bypass Surgery in California. Circulation 2018;137:1698-707.

27. Tatoulis J, Wynne R, Skillington PD, et al. Total arterial revascularization: achievable and prognostically effective - a multi-centre analysis Ann Thorac Surg 2015;100:1268-75.

28. Pu A, Ding L, Shin J, et al. Long- Term Outcomes of Multiple Arterial Coronary Artery Bypass Grafting. A Population - Based Study of Patients in British Columbia, Canada. JAMA Cardiol 2017;2:1187-96.

29. Habib RH, Dimitrova KR, Badour SA, et al. CABG versus PCI. Greater benefit in Long-Term Outcomes with Multiple Arterial Bypass Grafting. J Am Coll Cardiol 2015;66:1417-27.

30. Schwann TA, Hashim SW, Badou S, et al. Equipoise between radial artery and right internal thoracic artery as the second arterial conduit in left internal thoracic artery base coronary artery bypass graft surgery: A multi institutional study. Eur J Cardiothorac Surg 2016;49:188-95.

31. Navia D, Vrancic N, Piccinini F, et al. Is the second internal thoracic artery better than the radial artery in total arterial off pump coronary artery bypass grafting? A propensity score matched study. J Thorac Cardiovasc Surg 2014;147:632-8.

32. Saso S, James D, Vecht JA, et al. Effect of skeletonization of internal thoracic artery for coronary revascularization on the incidence of sternal wound infection. Ann Thorac Surg 2010;89:661-70.

33. Shi WY, Tatoulis J, Newcomb AE, et al. Is a third arterial conduit necessary? Comparison of the radial artery and saphenous vein in patients receiving bilateral internal thoracic arteries for triple vessel coronary disease. Eur J Cardiothorac Surg 2016;50:53-60.

34. Gaudino M, Puskas JD, Di Franco A, et al. 3 arterial grafts improve late survival. A meta-Analysis of propensity 
matched studies. Circulation 2017;135:1036-44.

35. Bertrand OF, Bélisle P, Joyal D, et al. Comparison of transradial and femoral approaches for percutaneous coronary interventions: a systematic review and hierarchical Bayesian meta-analysis. Am Heart J 2012;163:632-48.

36. Jolly SS, Yusuf S, Cairns J, et al. Radial versus femoral access for coronary angiography and intervention in patients with acute coronary syndromes (RIVAL): a randomised, parallel group, multicentre trial. Lancet 2011;377:1409-20.

37. Rashid M, Kwok CS, Pancholy S, et al. Radial Artery Occlusion After Transradial Interventions: A Systematic Review and Meta-Analysis. J Am Heart Assoc 2016;5. doi: 10.1161/JAHA.115.002686.

38. Kamiya H, Ushijima T, Kanamori T, et al. Use of the radial artery graft after transradial catheterization: is it suitable as a bypass conduit? Ann Thorac Surg 2003;76:1505-9.

39. Ruzieh M, Moza A, Siddegowda Bangalore B, et al. Effect of Transradial Catheterisation on Patency Rates of Radial Arteries Used as a Conduit for Coronary Bypass. Heart Lung Circ 2017;26:296-300.

40. Mounsey CA, Mawhinney JA, Werner RS, et al. Does Previous Transradial Catheterization Preclude Use of the Radial Artery as a Conduit in Coronary Artery Bypass Surgery? Circulation 2016;134:681-8.

41. Schwann TA, Zacharias A, Riordan CJ, et al. Does Radial Artery Use as a Second Arterial Graft Improve Coronary Artery Bypass Surgery Long-term Outcomes in Diabetics? Eur J Cardiothorac Surg 2008;33:914-23.

42. Toumpoulis IK, Theakos N, Dunning J. Does bilateral internal thoracic artery harvest increase the risk of mediastinitis? Interact Cardiovasc Thorac Surg 2007;6:787-91.

43. Deb S, Singh SK, Moussa F, et al. The long-term impact of diabetes on graft patency after coronary artery bypass grafting surgery: a sub-study of the multi center Radial Artery Patency Study. J Thorac Cardiovasc Surg 2014;148:1246-53.

44. Choudhary BP, Antoniades C, Branding AF, et al. Radial artery vosoreactivity in patients undergoing coronary artery bypass grafting. J Am Coll Cardiol 2007;50:1047-53.

45. Raza S, Blackstone EH, Houghtaling PL, et al. Similar outcomes in diabetes patients after coronary artery bypass grafting with single internal thoracic artery plus radial artery grafting and bilateral internal thoracic artery grafting. Ann Thorac Surg 2017;104:1923-32.
46. Lawton JS, Barner HB, Bailey MS, et al. Radial Artery Grafts in Women: Utilization and Results. Ann Thorac Surg 2005;80:559-63.

47. Dimitrova KR, Hoffman DM, Geller CM, et al. Radial artery grafting in women improves 15 -year survival. J Thorac Cardiovasc Surg 2013;146:1467-73.

48. Schwann TA, Engoren M, Bonnell M, et al. Comparison of late CABG survival effects of radial artery versus saphenous vein grafting in male and female patients. Ann Thorac Surg 2012;94:1485-91.

49. Pullan M, Kirmani BH, Conley T, et al. Th effect of patient sex on survival in patients undergoing isolated coronary artery bypass surgery receiving a radial artery. Eur J Cardiothorac Surg 2015;47:324-30.

50. Gardner TJ, Greene PS, Rykiel MF, et al. Routine use of the left internal mammary artery graft in the elderly. Ann Thorac Surg 1990;49:188-93.

51. Krane M, Voss B, Hiebinger A et al. Twenty years of cardiac surgery in patients aged 80 and older: riskd and benefits. Ann Thorac Surg 2011;91:506-13.

52. Lytle BW, Blackstone EH, Sabik JF, et al. The effect of bilateral internal thoracic artery grafting on survival during 20 postoperative years. Ann Thorac Surg 2004;78:200512; discussion 2012-4.

53. Schwann TA, Tranbaugh RF, Dimitrova KR, et al. Time-varying survival benefit of radial artery versus vein grafting: a multi-institutional analysis. Ann Thorac Surg 2014;97:1328-34.

54. Kurlansky PA, Traad EA, Dorman MJ, et al. Thirty-Year Follow-Up Defines Survival Benefit for Second Internal Mammary Artery in Propensity-Matched Groups. Ann Thorac Surg 2010;90:101-8.

55. Shi WY, Hayward PA, Fuller JA, et al. Is the radial artery associated with improved survival in older patients undergoing coronary artery bypass grafting? An analysis of a multicentre experience†. Eur J Cardiothorac Surg 2016;49:196-202.

56. Gaudino M, Glieca F, Luciani N, et al. Clinical and angiographic effects of chronic calcium channel blocker therapy continued beyond the first post-operative year in patients with radial artery grafts. Results of a prospective randomized investigation. Circulation 2001;104:I64-7.

Cite this article as: Tatoulis J, Schwann TA. Long term outcomes of radial artery grafting in patients undergoing coronary artery bypass surgery. Ann Cardiothorac Surg 2018;7(5):636-643. doi: 10.21037/acs.2018.05.11 